\title{
How the Grinch Couldn't Steal Christmas \\ An Elementary STEM Lesson
}

Julianna Berry ${ }^{1}$

${ }^{1}$ Affiliation not available

November 26, 2020

Grade Level: K-3rd

Suggested Time: 60-90 minutes

\section{Overview}

After watching a scene from the 1966 movie "How the Grinch Stole Christmas," students will use skills in engineering and measurement to "Grinch-proof" dollhouses with an array of materials. The students who design the most successful "Grinch-proof" trap will win a prize of candy canes!

\section{Vocabulary}

- Design

- Analyze

- Measure

- Ruler

- Force

\section{Objectives}

- Students will experiment with the strength of various materials.

- Students will consider various forces when designing structures.

- Students will learn how to plan a design.

- Students will work together to create a machine or that protects or catches a certain item.

- Students will use measurement tools to create appropriate-sized machines or traps.

- Students will observe the end result of their machines or traps to determine the functionality of it

- Students will analyze ways to improve their machines or traps.

\section{Next Generation Science Standards}

- 2-PS1-2 Matter and Its Interactions

Analyze data obtained from testing different materials to determine which materials have the properties that are best suited for an intended purpose.*

- K-2-ETS1-1 Engineering Design

Ask questions, make observations, and gather information about a situation people want to change to define a simple problem that can be solved through the development of a new or improved object or tool.

- K-2-ETS1-2 Engineering Design 
Develop a simple sketch, drawing, or physical model to illustrate how the shape of an object helps it function as needed to solve a given problem.

- 3-5-ETS1-1 Engineering Design

Define a simple design problem reflecting a need or a want that includes specified criteria for success and constraints on materials, time, or cost.

- 3-5-ETS1-3 Engineering Design

Plan and carry out fair tests in which variables are controlled and failure points are considered to identify aspects of a model or prototype that can be improved

Common Core Mathematics Standards

- CCSS.MATH.CONTENT.K.MD.A.1 -Measurement and Data

- CCSS.MATH.CONTENT.1.MD.A.1 - Measurement and Data

- CCSS.MATH.CONTENT.2.MD.A.1 - Measurement and Data

- CCSS.MATH.CONTENT.3.MD.D.8 -Measurement and Data

\section{Required Project Materials}

- Dollhouses (affordable ones can be found on the Target Online Store here (even comes with cardboard Christmas tree): https://www.target.com/p/color-your-own-corrugate-gingerbread-dollhousekit-wondershop-8482/

- Miniature Christmas Trees (if difficult to find, can be made out of green construction paper)

- Mesh Pieces

- String

- Cloth Pieces

- Popsicle Sticks

- Cardboard Pieces

- Scotch Tape

- Pebbles

- Dowel Sticks

- Rulers

- Paper

- Pencils

\section{Multimedia Resources}

- "How the Grinch Stole Christmas" 1966 Youtube Clip- https://www . youtube.com/watch?v=Z_SFt_ WNHfU

- Candy Canes (Prizes)

\section{Optional Multimedia Resources}

- "How the Grinch Stole Christmas" 1966 movie

- How the Grinch Stole Christmas book

\section{Before the Lesson/Background Information}

- Assemble the dollhouses and miniature trees if needed.

- Read or watch "How the Grinch Stole Christmas" to the class.

- Introduce rulers and what they are used for. 


\section{The Lesson}

\section{Part 1: Introduction (5 to 10 minutes)}

1. Play the Youtube clip of when the Grinch steals the Christmas toys and decorations from Whoville.

2. Tell students that today they are going to create ways to protect their house from the Grinch! They can either design a trap to catch the Grinch or a machine to protect the Christmas tree.

3. Inform students that they need the traps or machines to be the right size because the Grinch is very sneaky! Students need to measure what they're making as they build.

\section{Part 2: Build to Save Christmas (40 to 60 minutes)}

1. Assign students to groups of 2 or 3 and give them a dollhouse and miniature Christmas tree. Supplies for the build can be either passed out to the groups or put on a supply table for students to gather as needed.

2. Students will work together to plan, design, construct, measure and test their traps or machines with the various materials.

\section{Part 3: Testing the "Grinch Proof" House (15 to 20 minutes)}

1. Have each group demonstrate how their traps or machines work to the whole class.

2. Discuss with students how they would improve their traps.

3. Have class vote on who built the best trap and who built the best machine. Award candy canes to the winners! 